\title{
Correction to: A New Intraepithelial $\gamma \delta$ T-Lymphocyte Marker for Celiac Disease Classification in Formalin-Fixed Paraffin-Embedded (FFPE) Duodenal Biopsies
}

\author{
Alina Popp ${ }^{1,2} \cdot J_{\text {Juha Taavela }}$ · Paolo Graziano ${ }^{3} \cdot$ Paola Parente $^{3} \cdot$ Claudia Covelli $^{3} \cdot$ Carmela Lamacchia $^{4}$. \\ Angelo Andriulli ${ }^{3} \cdot$ Markku Mäki $^{1}$. Jorma Isola ${ }^{1,5}$
}

Published online: 25 November 2020

(c) The Author(s) 2020

\section{Correction to: Digestive Diseases and Sciences https://doi.org/10.1007/s10620-020-06680-x}

The original version of the article unfortunately contained an error in the first name and the surname of the all authors in the author group. Below is the corrected first name and the surname of the authors.

Alina Popp - Alina (First name); Popp (Surname)

Juha Taavela - Juha (First name); Taavela (Surname)

Paolo Graziano - Paolo (First name); Graziano (Surname)

Paola Parente - Paola (First name); Parente (Surname)

Claudia Covelli - Claudia (First name); Covelli (Surname)

Carmela Lamacchia - Carmela (First name); Lamacchia (Surname)

Angelo Andriulli - Angelo (First name); Andriulli (Surname)

Markku Mäki - Markku (First name); Mäki (Surname) Jorma Isola - Jorma (First name); Isola (Surname)

The original article has been corrected.

The original article can be found online at https://doi.org/10.1007/ s10620-020-06680-x.

Jorma Isola

jorma.isola@tuni.fi

1 Faculty of Medicine and Health Technology, Tampere University and Tampere University Hospital, Tampere, Finland

2 National Institute for Mother and Child Health, University of Medicine and Pharmacy "Carol Davila", Bucharest, Romania

3 Pathology Unit, Fondazione IRCCS Casa Sollievo della Sofferenza, San Giovanni Rotondo, FG, Italy

4 Department of the Science of Agriculture, Food and Environment, University of Foggia, Foggia, Italy

5 Jilab Inc, Tampere, Finland
Open Access This article is licensed under a Creative Commons Attribution-NonCommercial 4.0 International License, which permits any non-commercial use, sharing, adaptation, distribution and reproduction in any medium or format, as long as you give appropriate credit to the original author(s) and the source, provide a link to the Creative Commons licence, and indicate if changes were made. The images or other third party material in this article are included in the article's Creative Commons licence, unless indicated otherwise in a credit line to the material. If material is not included in the article's Creative Commons licence and your intended use is not permitted by statutory regulation or exceeds the permitted use, you will need to obtain permission directly from the copyright holder. To view a copy of this licence, visit http://creativecommons.org/licenses/by-nc/4.0/.

Publisher's Note Springer Nature remains neutral with regard to jurisdictional claims in published maps and institutional affiliations. 